\title{
O DESENVOLVIMENTO DO PSIQUISMO NA VIDA COTIDIANA: APROXIMAÇÕES ENTRE A PSICOLOGIA DE ALEXIS N. LEONTIEV E A TEORIA DA VIDA COTIDIANA DE AGNES HELLER
}

\author{
JoÃo HenRiQue RossLer
}

\begin{abstract}
RESUMO: Este trabalho pretende apontar algumas aproximações entre a psicologia de Leontiev e a teoria da vida cotidiana de Agnes Heller, mais precisamente aquilo que a filósofa húngara denomina como formas de pensamento, sentimento e ação típicas da cotidianidade. Nossa hipótese é a de que esse estudo pode trazer contribuiçôes para a psicologia sócio-histórica, especialmente no que se refere à compreensão das características do psiquismo humano numa sociedade marcada por processos de alienação, isto é, quando a estrutura da vida cotidiana cerceia o desenvolvimento intelectual, afetivo e moral dos indivíduos. Pretendemos, assim, contribuir para o entendimento daquilo que denominamos de "psiquismo cotidiano".
\end{abstract}

Palavras-chave: A. N. Leontiev. Agnes Heller. Teoria da vida cotidiana. Alienação. Psiquismo cotidiano.

THE DEVELOPMENT OF THE PSYCHE IN EVERYDAY LIFE: ESTABLISHING LINKS BETWEEN THE PSYCHOLOGY OF ALEXIS N. LEONTYEV AND AgNes HelleR's THEORY OF EVERYDAY LIFE

ABSTRACT: This work proposes to highlight some links between the psychology of A. N. Leontyev and the philosophical theory of everyday life of Agnes Heller - more precisely what she called the forms of thought, feeling and action that are typical of everyday life. Our hypothesis is that this kind of analysis should contribute to a social-historical psychology, especially when it comes to understanding certain features of the human psyche within an alienating society, that is, when the structure of everyday life limits the individual's

Formado em psicologia pela UNESP, campus de Bauru, e doutor em educação pela UNESP, campus de Araraquara; membro do Grupo de Pesquisa "Estudos Marxistas em Educação". E-mail: joheross@yahoo.com.br 
intellectual, affective and moral development. Through this paper, the author strives to contribute to an understanding of what could be called an "everyday psyche".

Key words: A. N. Leontyev. Agnes Heller. Theory of everyday life. Alienation. Everyday psyche.

\section{A formação do psiquismo humano no interior da cotidianidade}

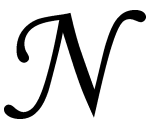

o campo dos estudos educacionais no Brasil, os livros $A$ individualidade para-si (Duarte, 1993) e Educação escolar, teoria do cotidiano e a Escola de Vigotski (Duarte, 1996) foram os primeiros a buscar uma articulação entre a teoria psicológica da assim chamada "Escola de Vigotski" e a teoria filosófica, da assim chamada "Escola de Budapeste", especialmente a teoria da vida cotidiana de Agnes Heller. Aos citados livros sucederam-se dissertaçôes de mestrado e teses de doutorado orientadas por Duarte, as quais analisam questóes no campo educacional tendo como referencial teórico ora a psicologia sócio-histórica, ora a teoria da vida cotidiana, ora ambas (Handam, 1997; Facci, 1998; Gonçalves, 1998; Vieira, 2000; Martins, 2001; Coelho, 2002; Rossler, 2003; Facci, 2003; Hollanda, 2003).

Procurando contribuir na direção da articulação das contribuições que essas duas escolas marxistas podem dar aos estudos educacionais, neste artigo procuraremos explorar algumas importantes aproximações entre a abordagem de Leontiev das relações entre a estrutura da atividade humana e a estrutura do psiquismo humano e a abordagem helleriana das relaçôes entre estrutura da vida cotidiana e as formas cotidianas de pensamento e ação.

Posto que o artigo de Duarte (2003) integrante deste número dos Cadernos CEDES aborda a questão das relaçôes entre a estrutura da atividade e a estrutura da consciência na psicologia de Leontiev, será suficiente mencionarmos aqui aqueles aspectos que dizem respeito mais diretamente ao tema deste artigo.

Conforme o psicólogo soviético Alexis N. Leontiev (1978), o psiquismo humano estrutura-se a partir da atividade social e histórica dos indivíduos, ou seja, pela apropriação da cultura humana material e simbólica, produzida e acumulada objetivamente ao longo da história da humanidade. Os objetos desse processo de apropriação, a saber, as objetivações produzidas pelo gênero humano, condensam 
em si, isto é, materializam trabalho humano, faculdades e aptidões humanas desenvolvidas ao longo da história da humanidade, e constituem-se em uma síntese dessa própria história.

A uma determinada estrutura objetiva da atividade do ser social corresponde, assim, uma dada estrutura subjetiva. Em outras palavras, a uma determinada realidade social, tanto material quanto simbólica, corresponde uma dada forma de consciência e personalidade. Desse modo, atividade, consciência e personalidade relacionam-se sempre dialeticamente. Leontiev diferencia atividade, ação e operação quando analisa a estrutura da atividade especificamente humana. Da mesma forma, ele diferencia sentido e significado ao analisar a estrutura da consciência humana. Em seus estudos, o referido autor deixa claro que o processo de constituição do psiquismo humano, pela apropriação dos bens culturais produzidos pela humanidade, consiste num processo mediado por outros indivíduos. Sendo assim, trata-se sempre e necessariamente de um processo educativo.

Heller (1989, 1994) divide a vida social humana em dois grandes âmbitos: o da vida cotidiana e o âmbito das esferas não-cotidianas da atividade social, sendo que o segundo tem sua gênese histórica no primeiro e sua existência já caracteriza um certo estágio de desenvolvimento da sociedade. A vida cotidiana é constituída a partir de três tipos de objetivações do gênero humano (objetivações genéricas em-si), que constituem a matéria-prima para a formação elementar dos indivíduos: a linguagem, os objetos (utensílios, instrumentos) e os usos (costumes) de uma dada sociedade. Já as esferas não-cotidianas se constituem a partir de objetivaçôes humanas superiores (objetivações genéricas para-si), isto é, mais complexas, como as ciências, a filosofia, a arte, a moral e a política.

Estes níveis qualitativamente distintos de objetivações se encontram em constante processo de transformação, na medida em que a atividade humana que produz e reproduz essas objetivaçôes tende, ao longo da história, a um grau de complexidade cada vez maior. $\mathrm{Na}$ medida em que se desenvolvem qualitativamente as atividades humanas, aprimoram-se os produtos materiais e simbólicos dessas atividades. Esses produtos, por sua vez, irão determinar um grau superior de desenvolvimento humano tanto material quanto psíquico, ou seja, tanto no que se refere aos aspectos objetivos da existência social humana quanto no que diz respeito às aptidóes e 
funções psíquicas dos indivíduos. Portanto, essas objetivações representam o próprio desenvolvimento histórico da humanidade, isto é, as marcas de sua evolução. Por sua vez, a existência das objetivações genéricas que compõem as esferas não-cotidianas da vida social indica o grau máximo de desenvolvimento alcançado pela humanidade, num dado momento histórico, ou seja, apontam para o que há de mais desenvolvido numa dada sociedade, em termos de suas produções socioculturais. Neste sentido, constituem-se naquilo que define o grau máximo que pode alcançar o desenvolvimento dos indivíduos naquela sociedade.

Para Heller, a formação dos indivíduos começa sempre nas esferas da vida cotidiana. Esse processo de formação se inicia já no momento de seu nascimento e inserção no universo cultural humano e se estende por toda a vida. E, como lembra Leontiev, trata-se, necessariamente, de um processo mediado, direta ou indiretamente, por outros indivíduos. Segundo Heller, a vida cotidiana é parte inerente à existência de todo e qualquer indivíduo. Nessa esfera do ser social, o indivíduo apropria-se da linguagem, dos objetos e instrumentos culturais, bem como dos usos e costumes de sua sociedade. Sem a apropriação dessas objetivações seria impossível a sua existência e convivência em qualquer sociedade humana, independentemente do nível de desenvolvimento dessa mesma sociedade. $\mathrm{Na}$ verdade, seria inviável a existência do indivíduo como ser humano. Neste sentido, a filósofa húngara afirma que a vida cotidiana é composta pelo conjunto das atividades voltadas para a reprodução da existência do indivíduo e a vida não-cotidiana é composta por aquelas atividades voltadas para a reprodução da sociedade. Assim, a cotidianidade consiste no espaço de satisfação das necessidades essenciais do indivíduo e, portanto, as atividades cotidianas são basicamente determinadas por motivaçóes de caráter particular. Por sua vez, as atividades não-cotidianas são determinadas por motivações genéricas, isto é, que aludem à universalidade do gênero humano, a qual também não pode ser considerada um dado natural já existente no início da história humana, devendo ser vista como um dos resultados possíveis do processo. Como a própria Heller menciona em vários momentos, há uma grande variabilidade no grau real de universalidade das motivações genéricas do comportamento individual, em especial se levarmos em conta o fato de que as objetivações genéricas para-si (ciência, arte, filosofia, moral e política) trazem as marcas da contraditoriedade de sua gênese histórica, a 
qual tem ocorrido até o presente em meio à divisão social do trabalho, à propriedade privada, enfim, em meio à luta de classes.

Segundo Heller, o indivíduo que vive a sua cotidianidade deve aprender a manipular os objetos, os instrumentos e utensílios de sua cultura. Deve se apropriar, por exemplo, do uso e do significado social do garfo, da faca, de um lápis, de um relógio etc. E como não existe apropriação que não seja mediada, direta ou indiretamente, por um outro indivíduo, esse processo pressupóe, por sua vez, a apropriação de certas relações sociais, bem como a apropriação da linguagem como forma básica de comunicação ou intercâmbio entre os indivíduos de um determinado grupo. Ao longo desse processo formativo, ocorrem ainda as apropriações das leis fundamentais da natureza. Todo ser humano virá a se apropriar, em algum momento de sua vida, da noção de que, ao se soltar um objeto no espaço, este cairá em direção ao chão, ainda que o indivíduo possa não saber explicar por que isso ocorre. Trata-se, nesse caso, de uma forma de conhecimento espontâneo, sem uma reflexão consciente, ainda não problematizado teoricamente. Em contrapartida, sabemos que qualquer existência em grupo, por mais primitiva que seja, pressupóe o estabelecimento de um certo conjunto de normas de convivência, isto é, pressupõe a existência de certos usos e costumes, ou seja, de certas normas explícitas ou tácitas de comportamento. Todo e qualquer indivíduo deve necessariamente se apropriar dessas regras de conduta social. É o caso, por exemplo, do vestuário, das normas que regem nosso comportamento sexual, das regras de conduta interpessoal em geral etc.

A autora ainda destaca que, ao longo da formação dos indivíduos em sua vida cotidiana, estruturam-se determinadas formas de pensamento, de sentimento e de ação típicas dessa esfera da vida social e necessárias para a própria reprodução da existência do indivíduo. Assim, podemos concluir que a formação dos indivíduos no âmbito da vida cotidiana determina a estruturação daquilo que poderíamos denominar de psiquismo cotidiano.

\section{As características do psiquismo cotidiano}

Dissemos anteriormente que para Leontiev o psiquismo humano, com suas faculdades e aptidões, estrutura-se a partir da atividade 
humana, isto é, das apropriaçóes sócio-históricas da cultura humana e que, portanto, a estrutura da consciência humana é diretamente condicionada pela estrutura da atividade social. O pensamento humano, por exemplo, é considerado por Leontiev como sendo sempre e essencialmente social, pois apóia-se em conceitos, generalizaçōes e operações lógicas socialmente estabelecidas. Ou seja, o pensamento dá-se a partir de determinadas operaçôes que estão objetivadas na linguagem, nos conhecimentos humanos, nos objetos, enfim, que estão sintetizadas nas objetivaçóes genéricas das quais os indivíduos se apropriam no seu processo de formação. Assim, se a atividade humana material é mediada por instrumentos sociais, a atividade mental intelectual também o é.

Em outras palavras, para Leontiev, o psiquismo é um produto da experiência sócio-histórica humana. Sintetiza a história e a experiência humanas acumuladas. Está, assim, determinado pelas condiçōes sociais nas quais vivem os indivíduos concretos, isto é, reproduz certas características da realidade material e social com a qual esses indivíduos interagem. Como a vida cotidiana se constitui numa esfera do ser social, poderíamos dizer que o psiquismo humano, de forma geral, sintetiza ou reproduz certas características da cotidianidade. O que significa dizer que, à estrutura material (objetiva) da vida cotidiana, corresponderia uma dada estrutura psíquica (subjetiva) com seus respectivos mecanismos psíquicos afetivos, intelectuais e comportamentais, isto é, com suas formas-padrão de pensamento, sentimento e ação. Portanto, a uma dada esfera da realidade social humana, qual seja, a vida cotidiana, corresponderia um determinado modo de funcionamento psíquico. Poderíamos falar, então, em um modo de funcionamento psíquico cotidiano, que envolveria formas típicas de perceber o mundo, raciocinar, sentir, comportar-se etc. Em suma, poderíamos então falar em determinadas formas de pensamento, sentimento e ação tipicamente cotidianas (Rossler, 2003, p. 54-55).

Mas quais seriam essas formas típicas do pensar, sentir e agir cotidiano? Em outras palavras, quais são as características dos pensamentos, sentimentos e açôes dos indivíduos no seu cotidiano e quais suas implicações para a vida dos indivíduos? É justamente nesse ponto que a teoria da vida cotidiana, tal qual formulada por Heller, pode fornecer valiosas contribuiçōes teóricas para a psicologia sócio-histórica, mais especificamente para a compreensão da estrutura e do funcionamento daquilo que aqui denominamos de psiquismo cotidiano. 
Ao analisar a estrutura da vida cotidiana, a autora elabora determinados conceitos que podem explicar certos padrões de funcionamento psíquico, de natureza cognitiva, afetiva e comportamental. Em outras palavras, explicita determinados modos de pensar, sentir e agir típicos da vida cotidiana.

Segundo a autora, a espontaneidade - ou o pensar e agir sem uma reflexão consciente e crítica - seria a característica dominante da vida cotidiana. A espontaneidade constitui-se em uma tendência de toda e qualquer atividade cotidiana. É necessário que atividades, pensamentos e ações dos indivíduos sejam espontâneos nessa esfera de sua vida, pois senão se tornaria inviável a produção e reprodução da sua existência social. Imaginem se os seres humanos se dispusessem a refletir sobre a forma e o conteúdo de todas as suas atividades, de todas as suas ações. Não conseguiriam realizar nem uma pequena parcela de suas atividades cotidianas e, assim, garantir sua reprodução como indivíduos. Se uma pessoa que vai atravessar uma rua se dispusesse a refletir e a considerar todas as variáveis físicas e matemáticas em jogo nesse seu comportamento, levaria um bom tempo fazendo cálculos sem sair do lugar. Assim, na vida cotidiana, as interaçôes sociais, o trabalho, o lazer, a formação dos hábitos e costumes, o uso da linguagem, a assimilação de certas idéias e de certas normas consuetudinárias de comportamento dão-se de forma essencialmente espontânea, não refletida, sem que se mantenha uma relação consciente para com todos esses elementos da vida humana.

$\mathrm{Na}$ vida cotidiana o indivíduo age, além de espontaneamente, a partir da probabilidade, isto é, da possibilidade. No cotidiano, entre a ação das pessoas e as suas conseqüências, estabelece-se sempre uma relação objetiva de probabilidade. Não seria viável para os indivíduos pretender, perante a heterogeneidade das atividades cotidianas, estabelecer com certeza científica as conseqüências de todas as suas ações. Além de inviabilizar a vida isso seria desnecessário. É possível para os indivíduos alcançar muito bem seus objetivos simplesmente a partir de ações determinadas por avaliações probabilísticas. Ao sair de casa para ir ao supermercado, por exemplo, o indivíduo não necessita determinar com rigor científico se chegará ao seu destino ou não e, na verdade, o indivíduo não dispõe de meios para tal cálculo. Existe já preestabelecida nesta ação ambas as possibilidades, e isso dentro de uma certa margem de erro, ou seja, de possibilidade 
de que fracassem as previsões, ainda que o sujeito envolvido no caso não pare para "refletir" sobre a questão. Pode ser que ele chegue ao supermercado mas pode acontecer um acidente grave durante o trajeto, levando o indivíduo a ser hospitalizado em vez de fazer compras no supermercado (Heller designa esses casos como as catástrofes da vida cotidiana).

A realização das atividades sobre a base da espontaneidade e da probabilidade aponta para o economicismo da vida cotidiana, isto é, a determinação dos pensamentos e das ações dos indivíduos a partir da "lei do menor esforço": menor dispêndio de energia, de tempo e de pensamento. $\mathrm{Na}$ vida cotidiana, os pensamentos e as ações visam sempre a sua efetivação de forma rápida, segura, num menor tempo e com o menor esforço possível, tanto físico quanto intelectual. E necessário que assim seja para que se viabilize o conjunto heterogêneo de atividades que compõem essa esfera da vida. Certos pensamentos, sentimentos e ações existem, manifestam-se e "funcionam" somente enquanto desempenham certa função na continuidade da vida cotidiana. Assim, não se manifestam com profundidade, amplitude e intensidade especiais, mas sempre de forma econômica.

Outra característica da estrutura da vida cotidiana é o pragmatis$m o$, isto é, a unidade imediata entre pensamento e ação. Trata-se do pensamento voltado para a realização de atividades cotidianas sem, no entanto, elevar-se ao nível da teoria. A teorização das atividades que os indivíduos realizam em sua vida cotidiana as tornaria complexas demais, demandando tempo e esforços desnecessários nesse âmbito da vida. Entre o que se faz e se pensa na cotidianidade, não haveria uma mediação teórica, reflexiva, crítica e aprofundada, mas sim uma determinação utilitária direta. $\mathrm{Na}$ vida cotidiana, os pensamentos e as ações são muito mais determinados por sua funcionalidade (viabilidade) imediata do que por razões de ordem teórica ou filosófica. ${ }^{1}$

O sentimento da confiança adquire um papel fundamental na vida cotidiana. Pelo fato de o pensamento cotidiano ser essencialmente espontâneo, probabilístico, "econômico", pragmático, ele vem acompanhado de um certo sentimento de confiança que lhe serve de suporte. Essa confiança é fortalecida por processos de controle social, mas mesmo esses processos não fornecem cem por cento de segurança. É o caso, por exemplo, da ação de tomar um táxi. Nós confiamos nas condições do veículo e do condutor deste. Tanto o veículo como 
o condutor são "avaliados" por meio de práticas institucionais, mas sempre restará uma margem de confiança pois nem o veículo nem o condutor são "checados" todos os dias. Isso não significa que a confiança seja um sentimento exclusivo da cotidianidade, mas sim que é indispensável nesse âmbito das atividades humanas. ${ }^{2}$

Outra característica marcante do pensamento cotidiano seria a ultrageneralização. Podemos perceber que, na vida cotidiana, os indivíduos agem ou por meio de generalizações tradicionalmente aceitas e difundidas na sociedade ou segundo generalizações que eles mesmos estabelecem a partir de suas próprias experiências particulares. Normalmente as pessoas não se orientam a partir de uma consideração mais precisa dos casos singulares que compóem a sua vida. Agem, isso sim, a partir de generalizações. Heller denomina este fenômeno de manejo grosseiro do singular. No cotidiano, não há como os indivíduos examinarem detalhadamente e com precisão as situações singulares, isto é, os problemas particulares com os quais se deparam. De fato, tendem sempre a situá-los sob alguma ótica mais geral, ou seja, tendem com freqüência a generalizar o seu pensamento, considerando as situações particulares de sua existência a partir de certas experiências anteriores ou simplesmente de generalizaçôes já existentes no seu meio social imediato. Em outras palavras, as pessoas recorrem à ajuda de vários tipos de ultrageneralização, isto é, de pensamentos ultrageneralizadores. São exemplos de ultrageneralizações: os juizos provisórios (juízos que se adquirem pela tradição coletiva ou pelas experiências individuais e que utilizamos de forma generalizada nas diversas situações da vida cotidiana) e os preconceitos, que têm a mesma origem dos juízos provisórios mas que não se apóiam no sentimento da confiança e sim no sentimento da "fé", e, por conseguinte, na particularidade, sendo por isso muito mais rígidos e enraizados afetivamente. Cabe destacar que, segundo Heller, o preconceito é uma categoria fundamental do pensamento e do comportamento cotidiano quando estes se alienam.

Outro exemplo de ultrageneralização seria a analogia. É por meio da analogia que se dá no cotidiano o conhecimento e o reconhecimento dos indivíduos no interior do universo das interaçóes sociais de caráter interpessoal. A partir dessa forma do pensar cotidiano, as pessoas são classificadas em algum tipo já conhecido no decorrer das experiências anteriores dos indivíduos. Essa classificação 
"tipológica" ou por tipos permite aos indivíduos se orientarem no mundo das relações interpessoais que compóem a cotidianidade.

Este é o caso também do uso dos precedentes. Cabe ressaltar que os precedentes são mais importantes para o conhecimento das situações cotidianas que o das pessoas. Os indivíduos comportam-se de determinadas formas ou adotam algumas atitudes em certas situações porque já tinham como referenciais alguns exemplos prévios extraídos de situaçóes similares vividas anteriormente.

Segundo a autora, ainda, não há vida cotidiana sem imitação. Tanto na assimilação dos instrumentos e utensílios, dos hábitos, dos costumes e dos usos de uma sociedade como no trabalho e na comunicação entre os seus membros, a imitação desempenha um papel bastante importante. $\mathrm{Na}$ vida cotidiana os indivíduos utilizam a imitação como um modo de aprender a agir segundo formas socialmente adequadas. Não é nenhuma novidade o fato de que a imitação consiste num elemento essencial dos processos de aprendizagem.

Um último elemento do agir e pensar cotidianos seria a entonação, ou seja, uma espécie de tom afetivo que existe à volta de cada pessoa. Esse elemento desempenharia um papel importante principalmente no que diz respeito à avaliação dos outros e à comunicação. Heller afirma ser esta categoria da cotidianidade uma ultrageneralização emocional. Quando essa entonação se aliena, poderíamos dizer, conforme a própria autora refere, que estamos diante de uma forma de "preconceito emocional".

Como podemos observar, estas categorias do pensar, do sentir e do agir cotidiano formam um conjunto articulado de processos psicológicos (afetivos, cognitivos e comportamentais) fundamentais para a existência e para a reprodução do indivíduo em sua vida cotidiana. Configuram, portanto, uma determinada estrutura psíquica inerente à vida de todo e qualquer indivíduo, uma vez que, como já dissemos, a cotidianidade é elemento constituinte da existência de todo e qualquer indivíduo em qualquer sociedade.

\section{A alienação da vida cotidiana}

Segundo Heller, na vida cotidiana, a presença de qualquer uma dessas formas de pensamento, sentimento e ação não é em si mesma 
um problema. Todavia, quando o indivíduo se torna incapaz de romper com tais formações psíquicas, mesmo nas situações de sua vida em que esses padrôes cotidianos de pensar, sentir e agir necessitem ser superados, estamos diante de um fenômeno de alienação. Em outras palavras, quando a estrutura da vida cotidiana se hipertrofia, tornando-se a única forma de vida do indivíduo; quando sua vida se resume num conjunto de atividades voltadas essencialmente para a sua reprodução, para a reprodução de sua particularidade, apresentando, assim, modos rígidos de pensar, sentir e agir, isto é, determinando um modo de funcionamento psíquico (intelectual e afetivo) cristalizado, que não pode ser rompido mesmo nas situações que o exigem; nesses casos, estamos diante de um fenômeno de alienação. Trata-se, portanto, de uma estrutura social alienada, de um cotidiano alienado e, conseqüentemente, de um psiquismo cotidiano alienado.

De acordo com Heller, o fenômeno de expansão da vida cotidiana e a cristalização das suas formas de pensamento, sentimento e ação são, essencialmente, determinados por uma totalidade social alienada. Assim, à alienação da estrutura material da sociedade corresponde um processo de empobrecimento da estrutura do psiquismo humano, na medida em que as condições materiais de vida típicas de uma sociedade marcada por relaçóes sociais de dominação, e, portanto, de alienação, impossibilitam a relação dos indivíduos para com as esferas nãocotidianas da existência humana, bem como a apropriação das formas de pensamento, sentimento e ação a elas inerentes. Em outras palavras, uma estrutura social alienada produz uma vida cotidiana alienada a qual, por sua vez, determina o esvaziamento da individualidade humana, impedindo o pleno desenvolvimento dos indivíduos, desenvolvimento esse que requer a existência de condiçóes objetivas e subjetivas favoráveis à apropriação das esferas materiais e simbólicas mais desenvolvidas do gênero humano, com a conseqüente objetivação individual no interior dessas esferas. Portanto, o cerceamento do indivíduo pela vida cotidiana consiste num processo tanto objetivo quanto subjetivo, ou seja, um processo tanto social quanto psicológico.

$\mathrm{O}$ indivíduo alienado é aquele que se alienou das esferas não-cotidianas da existência humana, estando circunscrito aos âmbitos cotidianos de sua existência particular, isto é, alienado da universalidade do gênero humano. Trata-se daquele indivíduo cujo desenvolvimento, cuja dinâmica entre os processos de apropriação e de objetivação estão 
restritos à esfera das objetivações materiais e simbólicas que constituem a genericidade em-si, restritos à esfera das motivações particulares e às formas do pensar, sentir e agir da vida cotidiana. De fato, essas atividades não-cotidianas demandam diferentes formas de pensar, sentir e agir. $\mathrm{Ou}$ seja, formas de pensamento, sentimento e ação próprios de um modo de funcionamento psíquico não-cotidiano.

Ora, temos aqui um círculo vicioso duplamente alienante, pois o cerceamento do indivíduo pelo seu cotidiano inviabiliza a apropriação das objetivaçôes genéricas para-si, bem como impede o indivíduo de se objetivar na esferas de objetivação genérica para-si, o que vem a reforçar ainda mais a alienação da própria esfera da vida cotidiana. Por sua vez, estando as esferas não-cotidianas da vida humana invadidas, em muitos casos, pela própria lógica da cotidianidade alienada, o acesso do indivíduo a essas esferas não pode ser considerado uma garantia de desenvolvimento do psiquismo individual. Entretanto, a luta coletiva pela generalização social do acesso a tais esferas (da qual constitui uma parte decisiva a luta pela universalização da escola pública e gratuita em todos os níveis de escolaridade) pode ter um efeito positivo sobre estas, na medida em que produza o questionamento sobre o tipo de lógica social que esteja direcionando o fazer, o pensar e o sentir nos âmbitos da ciência, da arte, da filosofia, da moral e da política. Essa mesma luta pode ter também um efeito positivo sobre a própria esfera da vida cotidiana, na medida em que produza o questionamento daquilo que Heller chamou de a hierarquia espontânea das esferas da cotidianidade.

O mencionado círculo vicioso apresenta-se como um fenômeno dominante nas sociedades marcadas pela desigualdade, marcadas por relações sociais de dominação e exploração de uma classe por outra. Os limites impostos ao ser humano pela cotidianidade, os quais determinam sua condição de indivíduo alienado, têm suas bases materiais na estrutura econômica e social da nossa sociedade. Portanto, correspondem a uma estrutura histórico-social determinada, que produz formas alienadas de objetivação, de produção de objetivações e, conseqüentemente, de apropriação dessas objetivaçóes.

$\mathrm{O}$ indivíduo alienado, conforme Heller, é o indivíduo que, por conta da alienação das relações sociais, isto é, por conta das relações de dominação que predominam em nossa sociedade e engendram as condições sociais e materiais de sua vida, não pode desenvolver-se plenamente a partir da apropriação de uma determinada esfera do gênero humano, qual seja, a genericidade para-si, transformando-a 
O desenvolvimento do psiquismo na vida cotidiana...

em órgãos de sua individualidade, ou seja, parte constitutiva do seu ser, de seu ser humano. Assim, os indivíduos vivenciam hoje um distanciamento crescente entre sua particularidade existencial e a relativa universalidade alcançada pelo gênero humano, entre o desenvolvimento da humanidade e o seu desenvolvimento como indivíduo particular, ou seja, seu desenvolvimento cultural, social e psicológico - intelectual, afetivo e moral. Os indivíduos experimentam, portanto, uma contradição cada vez mais intensa entre o enriquecimento crescente e sem precedentes do gênero humano, pela criação e produção de bens materiais e simbólicos cada vez mais complexos, e o empobrecimento e esvaziamento da sua individualidade humana.

Todavia, é importante frisar que para Heller o cotidiano não é sempre e necessariamente alienado, pois a alienação não constitui uma característica ontológica inerente ao ser social na sua dimensão cotidiana, isto é, intrínseca às objetivações genéricas que estão na sua base e às formas de pensamento e ação pelas quais o indivíduo se relaciona com o mundo imediatamente à sua volta. $O$ cotidiano torna-se alienado apenas em uma sociedade cuja forma de organização limita o pleno desenvolvimento dos indivíduos, quando a cotidianidade, ao invés de exercer a função de "infra-estrutura" da vida individual, sobre a base da qual o indivíduo pudesse se realizar em níveis cada vez mais elevados, torna-se uma barreira limitante, um obstáculo ao relacionamento entre o indivíduo e as esferas de objetivação genérica para-si (ciência, arte, filosofia, moral e política); aí sim estamos diante de um cotidiano alienado. O cotidiano torna-se sinônimo de alienação quando sua dinâmica impede os homens de se apropriarem da genericidade para-si, quando o indivíduo está preso ao reino daquelas necessidades materiais e psíquicas estritamente indispensáveis para reproduzir-se como indivíduo. Sendo que em nossa sociedade de classes isso significa, na maioria das vezes, estar preso ao que é necessário para sua sobrevivência quase que exclusivamente física, isto é, orgânica. O cotidiano torna-se alienado, portanto, quando a vida dos homens, quando seu ser estão preenchidos quase que exclusivamente pelas características, pelo conteúdo e pela dinâmica da cotidianidade; quando a forma de o homem se relacionar com suas atividades, o sentir, o agir e o pensar do homem, não vai além da estrutura das formas de pensamento, 
sentimento e ação típicas da vida cotidiana, as quais tomam conta, assim, da totalidade de sua existência objetiva e subjetiva. Em outras palavras, alienação está presente quando, por conta de determinadas condiçóes materiais, sociais e econômicas, a estrutura da vida cotidiana incha, hipertrofia-se, e penetra em todas as esferas da vida dos indivíduos. Nessas circunstâncias é raro que os indivíduos consigam distanciar-se, ainda que momentaneamente, das formas automáticas e espontâneas de agir, pensar e sentir da cotidianidade. Mais raro ainda é que eles cheguem a questionar a aparente naturalidade desse modo de ser.

Conforme já analisei em minha tese de doutorado (Rossler, 2003), a formação de um psiquismo cotidiano alienado, esvaziado e empobrecido intelectual, afetiva e moralmente, implica, necessariamente, a formação de um indivíduo incapaz de governar e conduzir a sua própria vida de forma livre e consciente, de ser o senhor de seus pensamentos, de suas vontades e de suas ações. $\mathrm{O}$ modo de funcionamento do psiquismo cotidiano alienado é sempre mais vulnerável a todas as formas de manipulação do comportamento, do pensamento e dos sentimentos, na medida em que a estrutura psíquica da cotidianidade alienada limita a capacidade de crítica e de reflexão consciente por parte do indivíduo.

Neste sentido, gostaríamos de ressaltar que este estudo toca na questão dos processos psicológicos (cognitivos e afetivos) pelos quais os indivíduos se relacionam com o mundo, com suas atividades, isto é, aborda as formas de pensamento e ação por meio das quais nos orientamos em nossas atividades e conduzimos nossa vida.

Em contrapartida, não podemos deixar de pressupor neste nosso estudo as formas de pensamento, sentimento e ação que consideramos desejáveis, quando se trata de romper com e superar a estrutura alienada da vida cotidiana. Ou seja, não podemos absternos de eleger o uso da razão, a crítica radical, a reflexão consciente, a análise coerente, a paixão pela verdade e pela transformação da realidade como as únicas formas possíveis de os indivíduos conduzirem livre e conscientemente a sua vida, alcançando, assim, um conhecimento objetivo que lhes permita desmistificar os processos de dominação e alienação da sociedade capitalista contemporânea. O que significa, em outras palavras, romper com a naturalidade com 
O desenvolvimento do psiquismo na vida cotidiana...

que é aceita a situação social e psicológica de alienação que marca a vida do indivíduo contemporâneo. ${ }^{3}$ Portanto, de forma alguma poderemos escapar à responsabilidade de nos posicionarmos criticamente ante o pensamento irracionalista que assola nossa sociedade de forma especialmente contundente neste início de século, uma vez que tal tipo de pensamento tem implicaçóes diretas sobre o degradante quadro histórico, social e cultural atual.

Concluindo, gostaríamos mais uma vez de afirmar que nosso objetivo com este trabalho consiste basicamente em propor que um estudo mais detalhado da teoria da vida cotidiana, elaborada por Heller, pode trazer contribuições bastante significativas para a psicologia, especificamente para um aprofundamento na compreensão de certas características do funcionamento psíquico humano, cognitivo e afetivo, bem como das circunstâncias da vida cotidiana sob as quais esse psiquismo se aliena e das características que, nesse caso, esse psiquismo aí assume. Imaginamos que esta seria uma das vias para construirmos estratégias eficazes de luta contra a alienação em todos os âmbitos da vida social, a começar pelo da vida cotidiana.

\section{Recebido em novembro de 2003 e aprovado em março de 2004.}

\section{Notas}

1. Em se tratando de uma sociedade fortemente alienada, como é o caso da sociedade capitalista, essa tendência ao pragmatismo pode exacerbar-se imensamente não só na vida cotidiana das pessoas como também em todas as demais esferas das atividades sociais. Isso não ocorre por acaso, sendo uma consequiência necessária de uma dinâmica social toda ela voltada para a produção e o consumo de mercadorias.

2. Não será possível, por uma questão de espaço, analisar neste texto a diferença, na teoria de Heller, entre os sentimentos de confiança e de fé. Apenas registramos que nessa teoria a presença da confiança na vida cotidiana não caracteriza processos de alienação, mas a presença da fé é necessariamente uma conseqüência de processos sociais alienantes.

3. Numa perspectiva marxista, que é tanto a de Leontiev como a de Agnes Heller quando ela elaborou a teoria da vida cotidiana, a superação da alienação não ocorre nem como um processo originariamente subjetivo nem como um processo individual. A superação da alienação exige a transformação da sociedade capitalista e a construção de uma sociedade socialista. Entretanto, como Heller enfatiza em mais de um momento, essa transformação da sociedade tem como parte necessária e importante a luta pelo máximo desenvolvimento da individualidade humana que for possível ainda no interior da sociedade capitalista. 


\section{Referências bibliográficas}

COELHO, S.M. A alienação em foco: dissertações e teses sobre a prática da professora alfabetizadora. 2002. 167f. Tese (Doutorado) - Faculdades de Ciências e Letras, Universidade Estadual Paulista, Araraquara.

DUARTE, N. A individualidade para-si: contribuição a uma teoria histórico-social da formação do individuo. Campinas: Autores Associados, 1993.

DUARTE, N. Educação escolar, teoria do cotidiano e a escola de Vigotski. Campinas: Autores Associados, 1996.

FACCI, M.G.D. O psicólogo nas escolas municipais de Maringá: a história de um trabalho e a análise de seus fundamentos. 1998. 252f. Dissertação (Mestrado) - Faculdade de Filosofia e Ciências, Universidade Estadual Paulista, Marília.

FACCI, M.G.D. Valorização ou esvaziamento do trabalho do professor?: uma análise crítico-comparativa da teoria do professor reflexivo, do construtivismo e da psicologia vigotskiana. 2003. 195f. Tese (Doutorado) - Faculdades de Ciências e Letras, Universidade Estadual Paulista, Araraquara.

GONÇALVES, R. Concepção histórico-social de ser humano e a educação escolar: contribuição para um diálogo entre a pedagogia histórico-crítica e a psicologia histórico-cultural. 1998. 219f. Dissertação (Mestrado) - Faculdade de Filosofia e Ciências, Universidade Estadual Paulista, Marília.

HANDAM, A.C. A educação escolar e a formação de conceitos cientificos. 1997. 127f. Dissertação (Mestrado) - Faculdade de Filosofia e Ciências, Universidade Estadual Paulista, Marília.

HELlER, A. Cotidiano e história. Rio de Janeiro: Paz \& Terra, 1989.

HELLER, A. Sociologia de la vida cotidiana. 4. ed. Barcelona: Península, 1994.

HOLLANDA, C.M.L. Da escola para casa e de casa para a escola: exercício de reflexão filosófica baseado em Agnes Heller. 2003. Tese (Dou- 
O desenvolvimento do psiquismo na vida cotidiana...

torado) - Faculdades de Ciências e Letras, Universidade Estadual Paulista, Araraquara.

LEONTIEV, A.N. O desenvolvimento do psiquismo. Lisboa: Livros Horizonte, 1978.

MARTINS, L.M. Análise sócio-histórica do processo de personalização de professores. 2001. 276f. Tese (Doutorado) - Faculdade de Filosofia e Ciências, Universidade Estadual Paulista, Marília.

ROSSLER, J.H. Sedução e modismo na educação: processos de alienação na difusão do ideário construtivista. 2003. 292f. Tese (Doutorado) - Faculdades de Ciências e Letras, Universidade Estadual Paulista, Araraquara.

VIEIRA, N.R. A relação entre o conhecimento científico e a realidade imediata do aluno no ensino de geografia. 2000. 167f. Dissertação (Mestrado) - Faculdade de Filosofia e Ciências, Universidade Estadual Paulista, Marília. 